\title{
DISPLACEMENT OF THE UPPER FEMORAL EPIPHYSIS IN A MAN OF TWENTY-SIX YEARS SUFFERING FROM SIMMONDS'S DISEASE FOLLOWING A HEAD INJURY
}

\author{
Raymond Farrow, London, England \\ Surgical Registrar, Westminster Children's Hospital; \\ Formerly at St Helier Hospital, Carshalton
}

Cases of Simmonds's disease complicated by displacement of the upper femoral epiphysis do not appear to be uncommon. Lerman and Means (1945) described two cases of Simmonds's disease following head injury. In the case to be described, a head injury, Simmonds's disease and displacement of the upper femoral epiphysis occurred in sequence in the same patient.

\section{CASE REPORT}

The patient, whose general build and physical state are described later, complained of pain in the left hip and shortening of the left leg. Two months previously he had slipped and fallen on the left hip. On examination, there was 2 inches of shortening of the left leg. Flexion, extension and adduction of the leg were full; abduction was limited to 30 degrees and medial

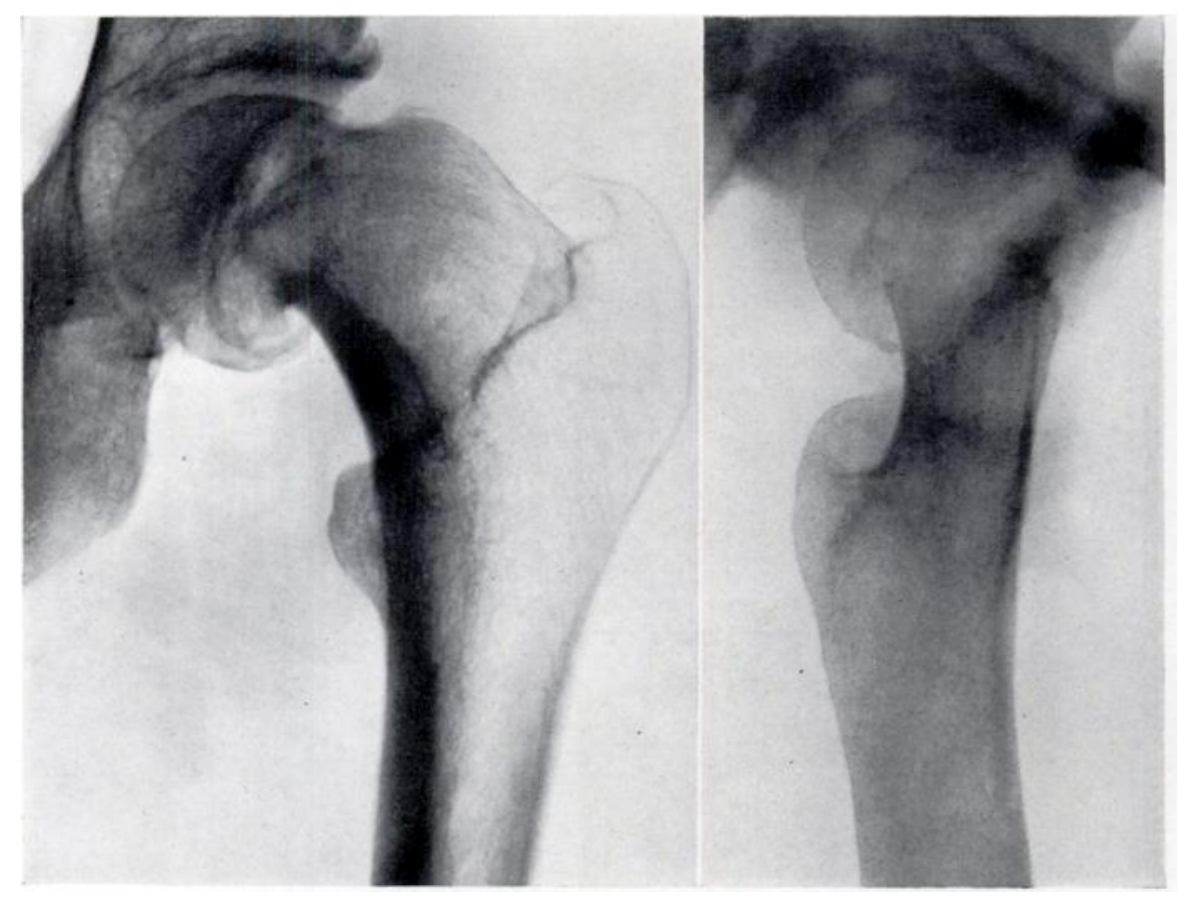

FIG. 1

and lateral rotation were absent. Radiographs showed displacement of the upper femoral epiphysis (Fig. 1).

During my examination of the hip I had been under the impression that I was dealing with a boy of about twelve to fourteen years of age and had attached no undue significance to the diagnosis of slipped upper femoral epiphysis. It was with great surprise that I discovered 
his age to be twenty-six years. I promptly extended my examination beyond the skeletal system. The patient was of slight build but not abnormally thin. He was five feet one inch in height; there was no disproportion between the arms, trunk and legs. The hair of the head was of normal texture but the skin of the face was sallow and the facial lines appeared deeper and more obvious than usual. The skin of the trunk was also sallow, dry and scaly. The voice was unbroken and the external genitalia were normally formed but of juvenile dimensions. Both testicles were in the scrotum but there was no evidence of either pubic or axillary hair. His appetite had always been poor but his weight had remained steady.

On further questioning it transpired that at the age of eleven years he had fallen from a table on to his head but had not lost consciousness. Three weeks after that injury he had begun to suffer increasingly severe headaches which were soon followed by attacks of vomiting. He had been admitted to a London children's hospital. Unfortunately the records of the hospital have since been destroyed but his mother was told that no fracture of the skull was discovered on radiographic examination, and that a day after admission a trephine hole was made in the left side of the skull. Later he had been discharged from hospital completely free from symptoms, in which state he has since remained.

There was no evidence of pituitary hypofunction in other members of the family. His own physical appearance and pre-puberty state do not seem to have caused him either embarrassment or concern. For the last eight years he had worked as a plumber's mate.

Investigations-His average daily pulse was 80 /minute; his morning temperature 97 degrees Fahrenheit and his evening temperature 98 degrees Fahrenheit. The haemoglobin estimation was 106 per cent and the basal metabolic rate was -37 per cent. A glucose tolerance test showed a fasting blood sugar of 35 milligrams per cent rising to 50 milligrams per cent in one and a half hours. The serum sodium was 322 milligrams per cent and the serum cholesterol was 310 milligrams per cent. Ketosteroid estimation showed an excretion of only 0.5 milligram in twenty-four hours. Stereoscopic radiographs of the skull and pituitary fossa showed no abnormality and a radiograph of one elbow showed an "epiphysial age" of about sixteen years. All these findings indicate a considerable deficiency in the secretions of the anterior lobe of the pituitary gland as is usually found in cases of Simmonds's disease.

\section{COMMENT}

It seems probable that the lesion in this case was a subdural haematoma. Lerman and Means (1945) point out that head injuries sufficient to injure the pituitary are usually sufficient to kill the patient. Only one of the two cases reported by them (that of a man of forty-eight) occurred after a non-penetrating injury and in that case the ketosteroid excretion was reduced to 1.4 milligrams in twenty-four hours and the blood sugar curve rose from 55 milligrams per cent to 91 milligrams per cent.

I am most grateful to Mr T. E. Stoker, of the St Helier County Hospital, for permission to record this case; to Dr Miller for pathological investigations and to Dr Lavelle for the loan of radiographs.

\section{REFERENCES}

Lerman, J., and Means, J. H. (1945): Hypopituitarism Associated with Epilepsy Following Head Injury. Report of Two Cases. Journal of Clinical Endocrinology, 5, 119. 